FACULdADE DE CIÊNCIAS ECONÔ MICAS DA UFRGS

MACROECONOMIA DO BRASIL PÓS-1994 LUIZ CARLOS BRESSER-PEREIRA

DESENVOLVIMENTO ECONOMMICO, PREFERÊNCIA PELA LIQUIDEZ E ACESSO BANCÁRIO: UM ESTUDO DE CASO DAS MESORREGIÓES DE MINAS GERAIS

MARCO CROCCO, CLAUDIO BARRA DE CASTRO, ANDERSON CAVALCANTE E VANESSA DA COSTA VAL

FRIEDMAN E O MONETARISMO: A VELHA TEORIA QUANTITATIVA DA MOEDA E A MODERNA ESCOLA MONETARISTA

GENTIL CORAZZAE RODRIGO L. KREMER

BOLLHAS RACIONAIS, CICLO DE PREÇOS DE ATIVOS E RACIONALIDADE LIMITADA: UMA AVALIACAOO CRITICA DOS MODELOS NEOCLÁSSICOS DE BOLHAS ESPECULATIVAS JOSÉ LUIS OREIRO

VULNERABILITY INDICATORS OF THE TWIN CRISES: THE EAST ASIAN EPISODE

TITO BELCHIOR SILVA MOREIRA

IMPACTOS POTENCIAIS DA NEGOCIAÇÃO DA ALCA SOBRE OS INVESTIMENTOS EXTERNOS EM SERVIÇOS PROFISSIONAIS NO BRASIL

MICHEL ALEXANDRE, OTAVIANO CANUTO E GILBERTO TADEU LIMA

TEORIA MARXISTA DO VALOR: UMA INTRODUÇẢO ALFREDO SAAD FILHO

UM ESTUDO EMPIRICO DOS CICLOS POLITICO. ECONOOMICOS NO BRASIL

ATHOS PRATES DA SILVEIRA PREUSSLER E MARCELO SAVINO PORTUGAL

RELENDO CHANDLER, WILLIAMSON E NORTH PARA ENTENDER O PROCESSO DE FORMACĀO DAS ESTRADAS DE FERRO NO BRASIL

JEFFERSON ANDRONIO RAMUNDO STADUTO

WEIMAR FREIRE DA ROCHA IR. E CLAIITON ATAIDES DE FREITAS

MATRIZ DE INSUMO-PRODUTO PARA A ECONOMIA TURISTICA BRASILEIRA: CONSTRUCCÃO E ANÁLISE DAS RELAÇÓES INTERSETORIAIS

FRANCISCO CASIMIRO FILHO E JOAQUIM JOSÉ MARTINS GUILHOTO

SEÇĀO ESPECIAL: AVALIAÇŌES INICIAIS DA POLITTICA ECONÓMICA DO GOVERNO LULA

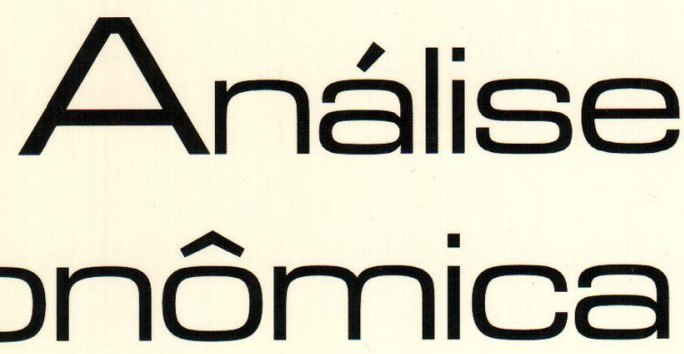


Universidade Federal do Rio Grande do Sul

Reitora: Profa. Wrana Maria Panizzi

Faculdade de Ciencias EConómicas

Diretora: Prof Pedro César Dutra Fonseca

Centro de Estudos e Pesquisas Economicas

Diretor: Prof. Gentil Corazza

Departamento de Ciéncias económicas

Chiefe: Prof. Ricardo Dathein

Curso de Pós. Graduação em Economia

Coordenador: Prof. Eduardo Pontual Ribeiro

Programa de Pós-Graduação em Desenvolvimento Rural

Coordenador: Prof. jalcione Almeida

CONSElHo EDITORIAL:

Carlos G. A. Mielitz Netto (UFRGS), Eduardo A. Maldonado Filho (UFRGS), Eduardo P. Ribeiro (UFRGS), Eleutério F. S. Prado (USP), Eugênio Lagemann (UFRGS), Fernando Cardim de Carvalho (UFRJ), Fernando Ferrari Filho (UFRGS), Fernando de Holanda Barbosa (FGV/RJ), Flávio Vasconcellos Comim (UFRGS), Gentil Corazza (UFRGS), Giácomo Balbinotto Netto (UFRGS), Gustavo Franco (PUC/RJ), Jan A. Kregel (UNCTAD), João Rogério Sanson (UFSC), Joaquim Pinto de Andrade (UnB), Jorge Paulo Araújo (UFRGS), Marcelo S. Portugal (UFRGS), Maria Alice Lahorgue (UFRGS), Paul Davidson (University of Tennessee), Paulo D. Waquil (UFRGS), Pedro C. D. Fonseca (UFRGS), Philip Arestis (Levy Economics Institut of Bard College), Roberto C. de Moraes (UFRGS), Ronald Otto Hillbrecht (UFRGS), Sabino da Silva Porto Jr. (UFRGS), Stefano Florissi (UFRGS) e Werner Baer (University of Illinois at UrbanaChampaign).

COMISSÃO EDITORIAL:

Eduardo Augusto Maldonado Filho, Fernando Ferrari Filho, Gentil Corazza, Marcelo Savino Portugal, Paulo Dabdab Waquil e Roberto Camps Moraes.

EDIroR: Prof. Fernando Ferrari Filho

Editor Adunnio: Prof. Gentil Corazza

SECRETÁrla: Clarissa Roncato Baldim

REVISÁO DE TEXTOS: Vanete Ricacheski

EDITORaÇão Eletrónica: Vanessa Hoffmann de Quadros

Fundador: Prof Antônio Carlos Santos Rosa

Os materiais publicados na revista Análise Econômica são da exclusiva responsabilidade dos autores. É permitida a reprodução total ou parcial dos trabalhos, desde que seja citada a fonte. Aceita-se permuta com revistas congêneres. Aceitam-se, também, livros para divulgação, elaboraçāo de resenhas e recensōes Toda correspondência, material para publicaçāo (vide normas na terceira capa), assinaturas e permutas devem ser dirigidos ao seguinte destinatário:

Análise Econômico

PROF FERNANDO FERRARI FILHO Revisła Análise Econômica - Av. João Pessoa, 52 CEP 90040-000 PORTO ALEGRE - RS, BRASL Telefones: (051) 316-3513 - Fax: (051) 316-3990 E-mail: rae@ufrgs.br

Ano 21, $n^{\circ} 39$, março, 2003 - Porto Alegre

Faculdade de Ciências Econômicas, UFRGS, 2003

Periodicidade semestral, março e setembro.

Tiragem: 500 exemplares

1. Teoria Econômica - Desenvolvimento Regional.

Economia Agrícola - Pesquisa Teórica e Aplicada -

Periódicos. I. Brasil

Faculdade de Ciências Econômicas,

Universidade Federal do Rio Grande do Sul 


\title{
Uma Estratégia Keynesiana para a Sustentabilidade de Longo Prazo da Dívida Pública
}

\author{
José Luís Oreiro* \\ Luiz Fernando de Paula**
}

\section{Introdução e Diagnóstico do Caso Brasileiro}

A economia brasileira tem apresentado um crescimento medíocre do PIB real nos últimos seis anos. Com efeito, excetuando o ano de 2000 no qual a taxa de crescimento foi superior a $4,0 \%$, desde 1998 o Brasil cresce a taxas inferiores a 2,0\% ao ano. Por outro lado, a dívida pública como proporção do PIB tem apresentado uma tendência inequívoca de aumento, passando de cerca de $49 \%$ em 1998 para mais de $56 \%$ ao final de 2002 . Tal coincidência de fenômenos nos leva a argüir se existiria alguma conexão entre a dinâmica da dívida pública e o crescimento do PIB real. De acordo com a teoria econômica convencional, não haveria nenhuma relação direta entre esses dois fenômenos: a taxa de crescimento do PIB real é determinada por fatores do lado da oferta - progresso tecnológico e crescimento populacional - sendo largamente independente do estoque (ou da variação) da dívida pública; ao passo que a dinâmica da dívida pública depende fundamentalmente do superávit primário e do comportamento da taxa de juros.

De uma perspectiva keynesiana, contudo, existem razóes para se acreditar que o baixo crescimento do PIB real e o aumento pronunciado da dívida pública como proporção do PIB observados na economia brasileira nos últimos anos têm uma causa comum, qual seja: a adoção de políticas monetária e fiscal de natureza contracionista pelo governo brasileiro desde 1998.

\footnotetext{
- Professor do Departamento de Economia da Universidade Federal do Paraná (UFPR) e pesquisador do CNPq. E-mail: joreiro@sociais.ufpr.br

" Professor da Faculdade de Ciências Econômicas da Universidade do Estado do Rio de Janeiro (UERJ) e pesquisador do CNPq. E-mail: Ifpaula@alternex.com.br.
} 
A taxa potencial de crescimento da economia brasileira está estimada em cerca de $4,5 \%$ ao ano ${ }^{1}$. Como a taxa média de crescimento do produto real tem se situado em cerca de $2,0 \%$ ao ano, segue-se que o crescimento da economia brasileira está restrito pela demanda agregada. Uma forte evidência empírica da existência de restrição de demanda ao crescimento é o comportamento do grau médio de utilização da capacidade produtiva da indústria. Os dados do IPEADATA mostram que o grau médio de utilização da capacidade produtiva tem se situado abaixo de $81 \%$ nos últimos anos, tal como podemos visualizar no Gráfico I abaixo.

\section{Gráfico 1: Dados Trimestrais do Grau de Utilização da Capacidade Pro- dutiva da Indústria Brasileira (2000-2003)}

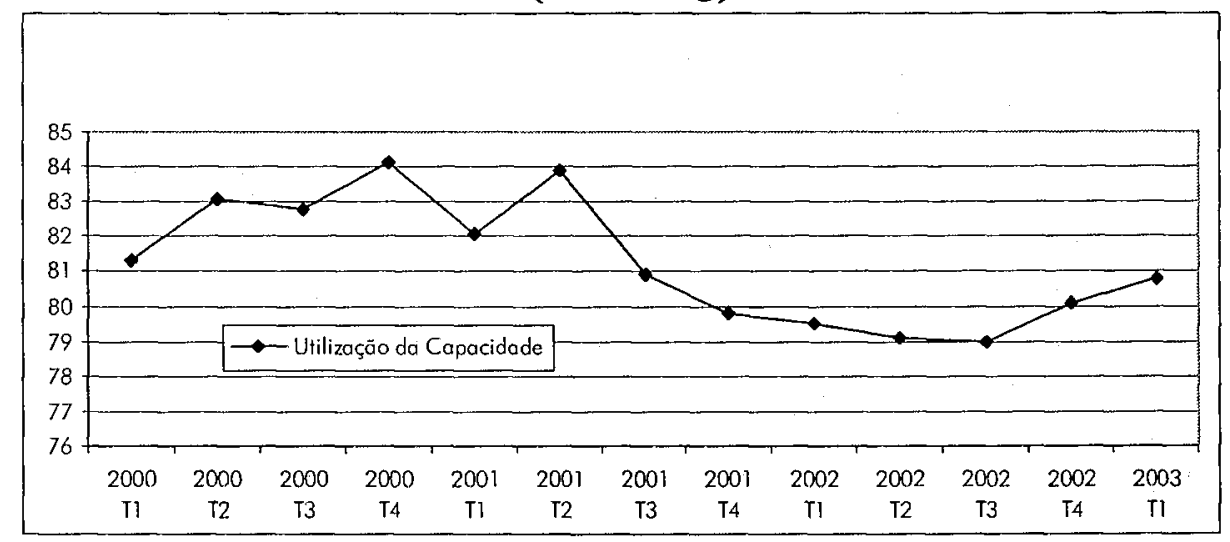

Fonte : IPEADATA.

\footnotetext{
${ }^{1}$ Esse número é obtido ao se somar à taxa atual de crescimento da força de trabalho no Brasil - de cerca de $2.5 \%$ ao ano - uma estimativa relativamente conservadora de crescimento da produtividade do trabalho na indústria em torno de $2,0 \%$ ao ano. Deve-se ressaltar que os procedimentos usuais de cálculo do crescimento da produtividade do trabalho, baseados do conceito de produtividade total dos fatores de produção (TFP), tendem a subestimar o crescimento da produtividade do trabalho. Isso se deve a forma pela qual a TFP é calculada. De fato, a TFP é definida como a diferença entre o crescimento do produto real e a parcela desse crescimento que pode ser atribuída às contribuições do capital e do trabalho. Ou seja, a TFP é uma variável puramente residual. Está claro que se o crescimento do produto for diminuído devido a um choque contracionista de demanda agregada, essa diferença irả diminuir, reduzindo assim o ritmo de crescimento da produtividade do trabalho. No entanto, essa reduçāo não revela uma diminuição do ímpeto real de crescimento da produtividade, mas apenas o fato de que o produto efetivo não acompanhou o crescimento do produto potencial devido à restrição de demanda agregada.
} 
A política monetária tem tido uma natureza fortemente contracionista no Brasil desde a implantação do Plano Real. Isso se explicava, em parte, pelo dilema "juros-câmbio" que o regime de crawling-peg adotado pelo Brasil impunha às autoridades monetárias até 1999. Contudo, a mudança no regime cambial brasileiro em janeiro desse ano para flutuação suja não conseguiu reduzir as taxas reais de juros para níveis compatíveis com os prevalecentes nos demais países emergentes. Com efeito, o Brasil continua como o país com a maior taxa real de juros entre esse grupo de países, conforme pode ser visualizado pelo Gráfico 2 abaixo:

\section{Gráfico 2: Taxas de Juros Reais de Curto Prazo em 23 Economias Emer- gentes (\% a.a.)}

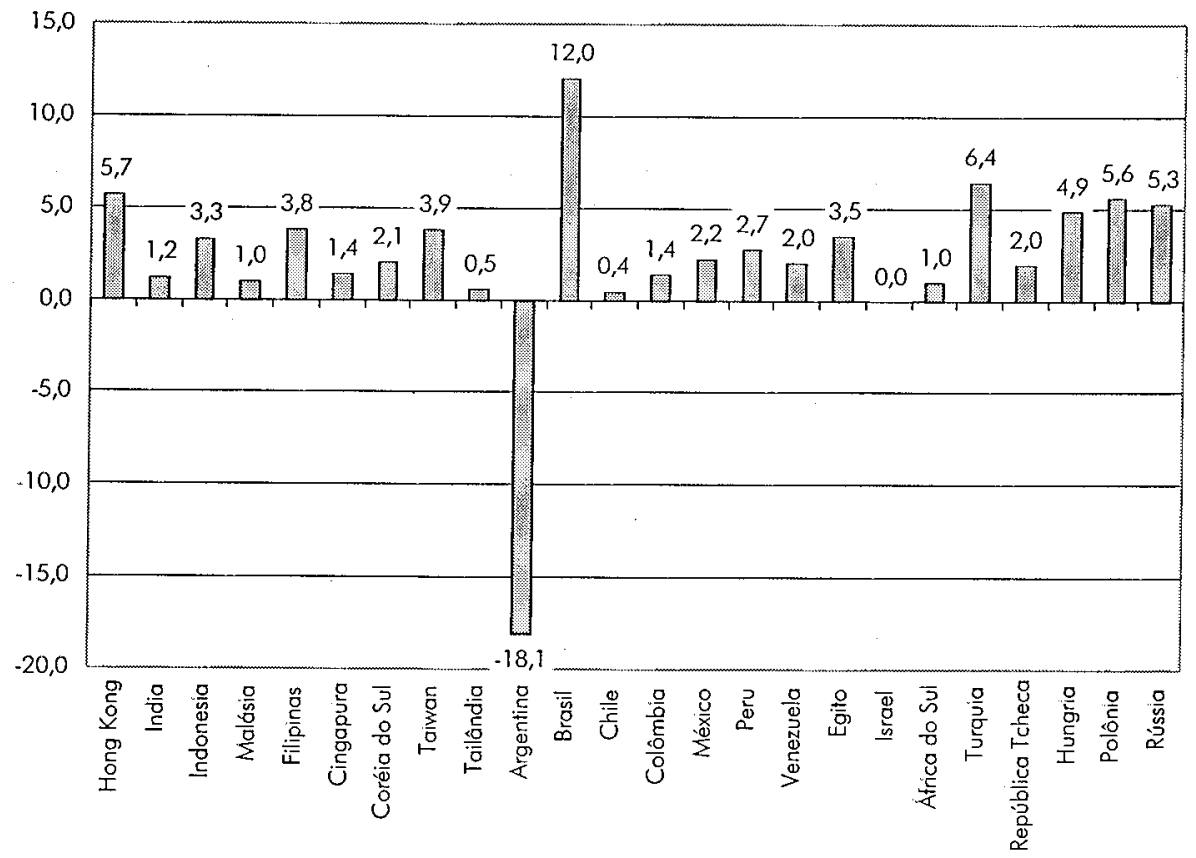

Fonte : Economia \& Conjuntura, Dezembro de 2002.

A taxa real de juros no Brasil é tão elevada por duas razões fundamentais. Em primeiro lugar, porque é necessário atrair capitais externos para atender à elevada necessidade de financiamento externo da economia brasileira, resultante da combinação de um elevado déficit em transações correntes como proporção do PIB com uma elevada dívida externa como proporção do PIB (cf. Paula, 2003). Em 
segundo lugar, a manutenção da taxa de inflação num patamar compatível com a obtenção das metas de inflação, num ambiente macroeconômico caracterizado pela existência de câmbio flutuante e mobilidade de capitais, exige que a taxa doméstica de juros seja alta para evitar o repasse para os preços (efeito pass-through) da depreciação do câmbio nominal nos momentos em que ocorre um fluxo de saída de capitais. Como os fluxos de capitais têm apresentado uma "volatilidade excessiva" nos últimos anos, segue-se a taxa nominal (e real) de juros tem que ser mantida permanentemente num patamar elevado ${ }^{2}$.

A combinação de uma alta taxa real de juros com baixo crescimento do PIB real faz com que a estabilização da dívida pública como proporção do PIB só seja possível se o governo operar com um elevado superávit primário. Em outras palavras, o problema fiscal brasileiro é endógeno, isto é, resultante da combinação entre o desequilibrio externo da economia brasileira - consubstanciado na elevada necessidade de financiamento externo - e o regime de política econômica, caracterizado pela tríade metas de inflação/mobilidade de capitais/câmbio flutuante (cf. Oreiro, 2002).

Neste artigo iremos analisar as condições necessárias para a sustentabilidade de longo-prazo da dívida pública interna. Para tanto, será apresentada uma alternativa keynesiana de longo prazo (até 2011) para superação do problema do endividamento público no Brasil, que permita ao mesmo tempo a adoção de uma política fiscal mais relaxada, contrapondo-a a uma estratégia conservadora, inspirada na concepção da equipe econômica do Governo Lula.

\section{Sustentabilidade da Dívida Pública: Cenários e Estratégias ${ }^{3}$}

A dívida pública líquida como proporção do PIB, que vinha se mantendo estável até meados de 2001 (cerca de 50\% do PIB), cresceu rapidamente desde então, devido à elevação da taxa de juros real (para patamares superiores a $12 \%$ a.a.) e a redução do crescimento do PIB real para $1,51 \%$ em 2001. Nossos cálculos sobre o superávit primário requerido para estabilizar a relação dívida/PIB -

${ }^{2}$ Uma análise mais aprofundada do porquê a taxa real de juros no Brasil é tão elevada pode ser obtida em Bresser 8 Nakano (2002).

${ }^{3}$ Esta seção está baseada parcialmente em Oreiro, Paula e Sicsú (2003). 
determinado pela fórmula $s^{*}=[(\mathrm{r}-\mathrm{g}) /(1+\mathrm{g})] b^{4}$, em que $r$ é a taxa real de juros, g é a taxa de crescimento do PIB real, $b$ é o superávit primário como proporção do PIB - é que o mesmo seria de cerca de $5,0 \%$ do PIB (superávit requerido I). Como o superávit efetivo no período 2000/02 - inferior a 4,0\% do PIB - é menor do que o superávit requerido, a condição de sustentabilidade do endividamento público é violada, e a relação dívida pública/PIB entra numa trajetó ria ascendente. Considerando que o crescimento da dívida pública ocorreu, em parte, em função do efeito da desvalorização cambial sobre a dívida, calculamos também o superávit requerido tomando como base a relação dívida pública/PIB prevalecente em julho de 2000 (superávit requerido II). Como pode-se observar no Gráfico 3, o superávit requerido assim calculado se comporta de forma similar ao anterior, deixando inalterada a conclusão acima.

Supondo um endividamento inicial de 56,53\% do PIB - valor alcançado em dezembro de 2002 - e a estabilidade do câmbio real a divida pública permanecerá relativamente estável até 2011 , alcançando o patamar de 56,04\% do PIB (Gráfico 4), tomando como base as premissas iniciais de uma simulação realizada pelo Banco Central do Brasil em 2002: taxa de inflação média de 3,5\% a.a., taxa real de juros de 9,0\% a.a., taxa de crescimento do PIB de 3,5\% a.a., e superávit primário mantido em 3,75\% do PIB (Cf. Goldfajn, 2002).

Nesse contexto, para se reduzir o endividamento do setor público seria necessário um superávit primário em todo o período de cerca de $4,5 \%$ do PIB. Com esse superávit, a dívida pública se reduziria para 48,03 \% do PIB em 2011, de acordo com as nossas estimativas (ver Gráfico 5). Neste contexto, existem duas questões que são fundamentais para analisar a evolução futura do endividamento do setor público. Em primeiro lugar, devemos perguntar se um superávit primário superior a 4,0\% do PIB, por um período continuado, é politicamente sustentável, ou seja, se a sociedade brasileira está ou não disposta a transferir para o setor público uma parcela tal da renda nacional que seja compativel com essa meta de superávit primário.

Acreditamos não ser politicamente viável - a médio e longo-prazo - a manutenção do superávit primário em um patamar superior a $3,0 \%$ do PIB $^{5}$. Com efeito, a carga tributária brasileira, situada em

\footnotetext{
${ }^{4}$ A discussão técnica sobre as condições de sustentabilidade da dívida pública é baseada em Argandoña et alii (1996).

${ }^{5}$ A sustentabilidade da dívida pública deve ser avaliada não apenas do ponto de vista econômico, como também político. Ver, a esse respeito, International Monetary Fund (2002).
} 
$35 \%$ do PIB, é bastante elevada quando comparada com a prevalecente em países que possuem um nível de renda per capita semelhante ao Brasil. Paralelamente, não há muito espaço para a redução do gasto público. Os servidores públicos federais estão sem reajuste de salário há quase oito anos; a disponibilidade de recursos do governo federal para o custeio de gastos de investimento para 2003 era inicialmente de apenas 7 bilhões de reais; por fim, há patentes deficiências na infra-estrutura básica da economia brasileira.

\section{Gráfico 3: Superávit Efetivo X Superávit Requêrido para Estabilizar a Dívida Pública (2000-2002)}

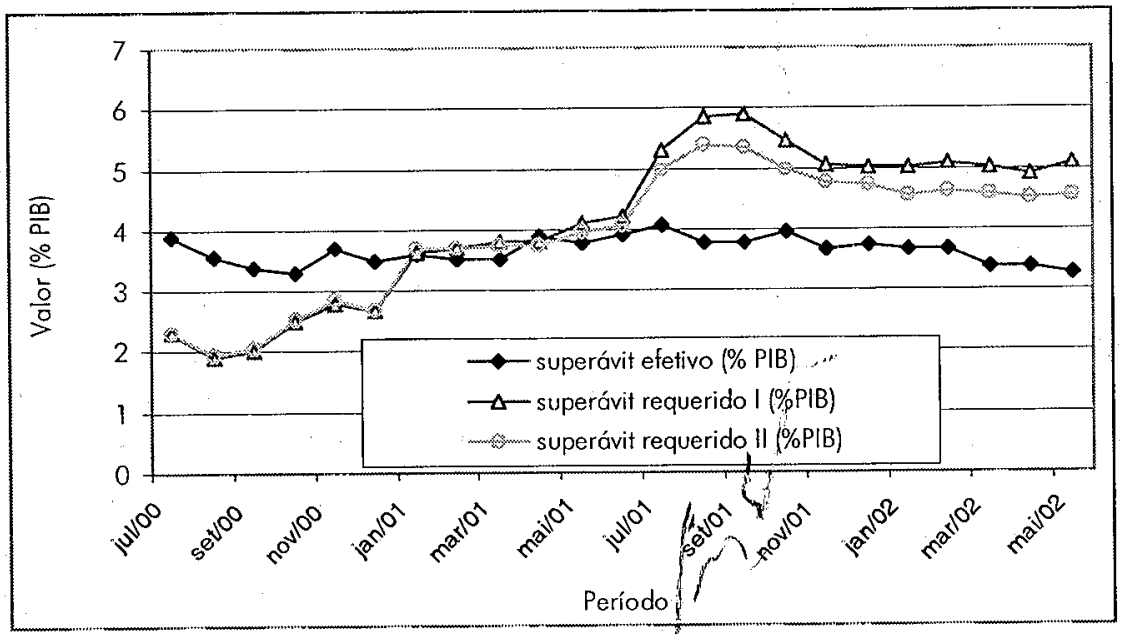

Fonte: Elaboração própria (dados da Conjuntura Econômica - julho 2002)

\section{Gráfico 4: Evolução da Dívida Pública Líquida/PIB superávit primário de $3,75 \%$ do PIB}

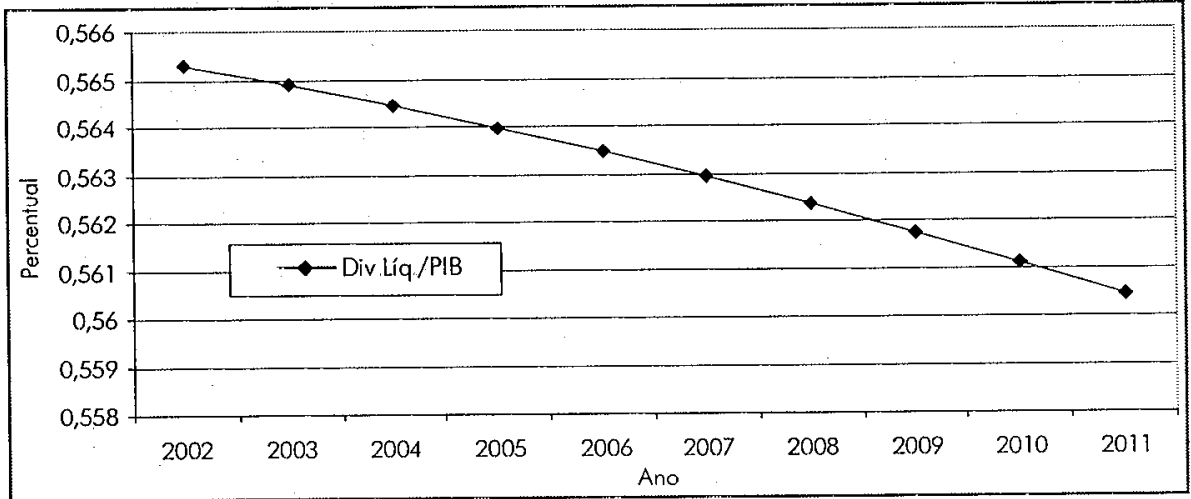


Uma segunda questão importante é saber se nāo existiriam estratégias alternativas de redução do endividamento público que, respeitando os contratos e a estabilidade de preços, fossem capazes de reduzir a relação dívida/PIB, sem exigir um superávit primário tão grande. Essa estratégia alternativa seria gradualista, sendo implementada após a restauração de um quadro de certa normalidade nas condições macroeconômicas do país - retorno da inflação para um patamar inferior a $1 \%$ ao mês, retorno das linhas de crédito externo para o financiamento das exportações, risco-Brasil abaixo dos 1.000 pontos base, etc. Nesse contexto, o governo iria gradualmente reduzir a taxa nominal de juros para níveis compatíveis com o próprio risco-país (o que significa uma SELIC em torno de $16 \%{ }^{\text {aa }}$ ).

Essa estratégia alternativa de redução do endividamento público estaria baseada em quatro pilares:

(i) Redução do superávit primário para um patamar médio de 3,0\% do PIB válido para os próximos 10 anos;

(ii) Adoção de um sistema de "crawling-peg" ativo no qual o Banco Central fixa ex-ante a taxa de desvalorização do câmbio tendo em vista a estabilidade da taxa real de câmbio e da taxa de inflação, a qual não deve superar uma "meta implícita" de 8,5\% ao ano até 2011;

(iii) Redução da taxa nominal de juros para um patamar compatível com a obtenção de uma taxa real de juros de 6,0\% ao ano;

(iv) Adoção de controles de entrada e saída de capitais de curto-prazo, cujo objetivo é desvincular a taxa doméstica de juros da "camisa de força" imposta pela paridade descoberta da taxa de juros.

Os pilares (i) e (iii) têm como fundamento a idéia de que a economia brasileira está crescendo a um ritmo muito inferior ao potencial, devido à insuficiência de demanda agregada, a qual resulta de uma combinação entre política fiscal e monetária contracionistas. Essa insuficiência de demanda agregada se reflete num baixo grau de utilização da capacidade produtiva, inferior a $81 \%$, tal como foi visto na seção anterior.

A adoção de controles de capitais é vista como essencial para o sucesso dessa estratégia de estabilização da dívida pública. De fato, o alto grau de abertura da conta de capitais no Brasil é um dos fatores que fazem com que a taxa nominal e real de juros no Brasil esteja entre as mais altas do mundo. Sendo válida a "paridade descoberta da taxa de juros", segue-se que a taxa de juros nominal doméstica 
deve ser igual à soma da taxa de juros internacional com o riscopaís e a expectativa de desvalorizaçāo da taxa de câmbio.

No caso brasileiro, a taxa de juros internacional de referência é a taxa de juros dos bônus de três anos do governo americano ${ }^{6}$. Essa taxa era de $2,06 \%{ }^{\text {aa }}$ em abril de 2003 (IPEADATA). No final do primeiro semestre de 2003, o risco-país estava situado em cerca de 800 pontos base, o que significa um "prêmio de risco" de cerca de $8,0 \%$ aa. Por fim, supondo válida a hipótese da paridade do poder de compra, então a expectativa de desvalorização do câmbio nominal é igual à diferença entre a inflação doméstica e a inflação internacional. A expectativa de inflação no Brasil para 2003, tomando como base a meta de inflação deste ano, é de 8,5 \%. A inflação nos Estados Unidos, por sua vez, deve ser inferior a $2,0 \%$ em 2003, de tal forma que o diferencial entre as taxas de inflação deve se situar em $6,5 \%$. Daqui se segue que o valor da taxa nominal de juros que iguala a rentabilidade esperada ajustada pelo risco dos títulos americanos e dos títulos brasileiros é igual a $16,5 \%^{\text {aa }}$ no caso da economia brasileira. Esse valor gera uma taxa real de juros igual a $8,0 \%^{\text {aa }}$.

A estratégia de estabilização da dívida pública delineada nos parágrafos anteriores prevê uma taxa real de juros de $6,0 \%^{\mathrm{aa}}$. Isso significa que existe uma incompatibilidade entre o valor da taxa real de juros que garantiria o equilíbrio interno da economia brasileira ou seja, um crescimento igual ao potencial de $4,5 \%^{\text {aa }}$ - e o valor da taxa real de juros para o qual se garante o equilibrio na conta de capitais do balanço de pagamentos. Especificamente, a taxa real de juros que garante o equilibrio interno é 200 pontos base menor do que a taxa de juros que garante o equilibrio externo.

Nesse contexto, a fixação da taxa nominal de juros num patamar compativel com o equilibrio interno da economia brasileira iria gerar, na ausência de controles de capitais, um movimento de fuga de capitais em direção a outros mercados financeiros. Tal movimento geraria, num regime de câmbio flutuante, uma forte depreciação do câmbio nominal que, por sua vez, seria transmitida para os preços domésticos, gerando um forte aumento da taxa de inflaçăo. Num regime de crawling-peg, haveria uma significativa redução das re-

\footnotetext{
${ }^{6}$ Isso porque o prazo médio de vencimento dos tírulos emitidos pelo governo e pelas empresas brasileiras no exterior está em torno de três anos. Dessa forma, o rendimento na maturidade dos títulos americanos seria a taxa de referência para o cálculo do rendimento na maturidade dos títulos brasileiros.
} 
servas internacionais do país e, por conseguinte, uma grande redução da base monetária. $\mathrm{Na}$ ausência de operações de esterilização, essa contração monetária teria fortes efeitos recessivos sobre a economia, impedindo a retomada do crescimento.

Do exposto, segue-se que a compatibilização entre equilíbrio interno e externo da economia brasileira requer a imposição de restrições à abertura da conta de capitais do balanço de pagamentos da economia brasileira. Em outras palavras, faz-se necessário a introdução de controles de saída para impedir que a redução da taxa doméstica de juros - necessária para a retomada do crescimento seja seguida por uma fuga de capitais do país?

\section{Gráfico 5: Evolução da Relação Dívida/PIB sob Diferentes Estratégias de Política Econômica}

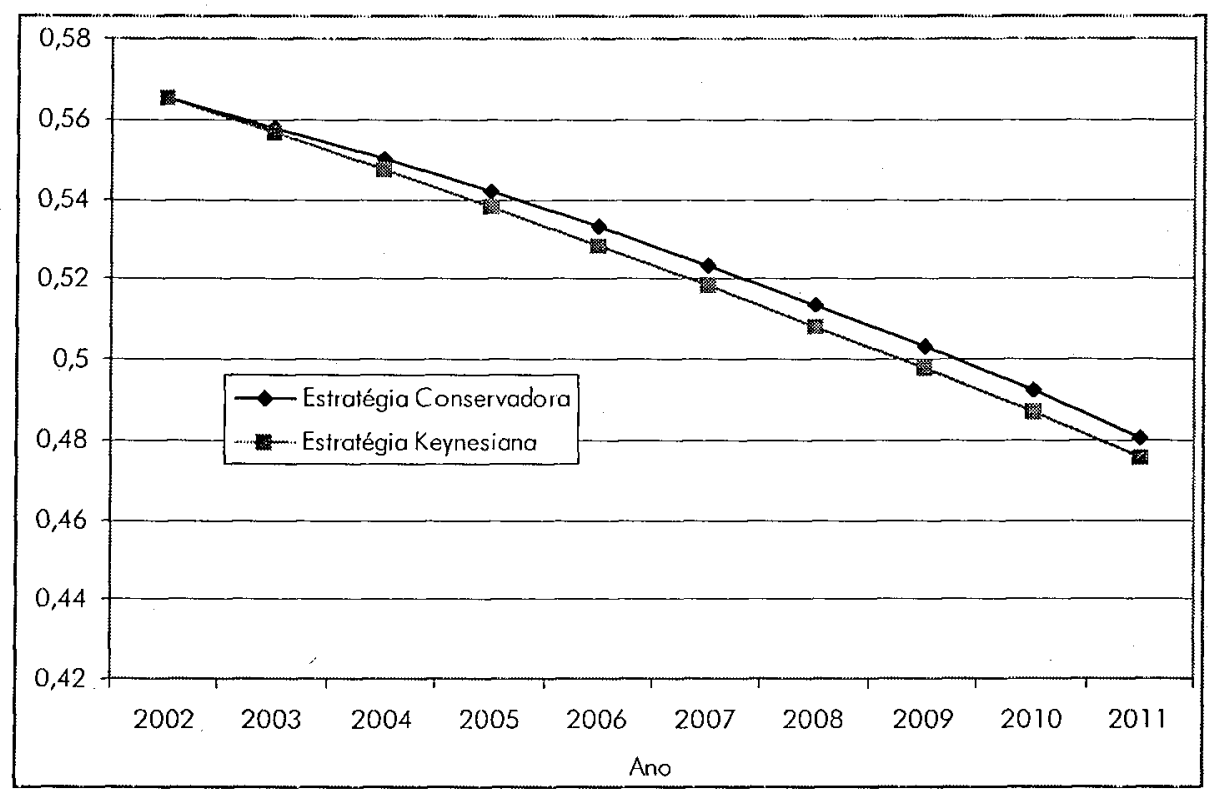

\section{Conclusão}

Isto posto, este artigo apresentou duas estratégias possiveis para reduzir o endividamento público. A primeira estratégia (intitulamos "Estratégia Conservadora"), inspirada nas concepções da equipe

\footnotetext{
${ }^{7}$ Maiores detalhes sobre a proposta de controles de capitais para a economia brasileira podem ser obtidos em Paula, Oreiro e Jonas (2003).
} 
econômica do Governo Lula, seria manter um superávit primário médio de $4,5 \%$ do PIB e manter a taxa real de juros num patamar de $9,0 \%$ ao ano, o que resultaria - numa estimativa otimista - num crescimento de $3,5 \%$ do PIB, abaixo do potencial da economia brasileira. A segunda estratégia (intitulamos "Estratégia Keynesiana"), de inspiração Keynesiana, se baseia no reconhecimento de que produto efetivo está abaixo do potencial e que, portanto, é possível realizar uma grande redução da taxa nominal de juros, mantendo-se a inflação sob controle e, ao mesmo tempo, alcançando um crescimento médio do PIB da ordem de $4,5 \%^{\text {aa }}$. Nesta estratégia, o superávit primário é mantido, mas reduzido para um patamar de 3,0\% do PIB. Tal como mostra no Gráfico 5, a dívida pública com respeito ao PIB se reduz no cenário básico de ambas as estratégias para um patamar próximo a $48 \%$ até 2011 . Contudo, a "Estratégia II" teria vantagem de ser compatível com o crescimento do PIB a uma taxa igual à potencial e com o "afrouxamento" da restrição fiscal.

\section{Referências Bibliográficas}

ARGANDOÑA et alii. (1996). Macroeconomía Avanzada: modelos dinámicos y teoría de la política económica. McGraw Hill: Madri.

BRESSER PEREIRA, L.C., E Y.NAKANO (2002). "Uma estratégia de desenvolvimento com estabilidade". Revista de Economia Política: 22 (3): 146-177, jul./set.

ECONOMIA E CONJUNTURA, Dezembro de 2002.

GOLDFAJN, I. (2002). "Há Razões para Duvidar que a Dívida Pública é Sustentável?" Notas Técnicas do Banco Central do Brasil n. 25.

INTERNATIONAL MONETARY FUND. (2002). "Assessing Sustainability". In Public Information Notice 2/69. www.imf.org/external/np/pdr/sus/2002/eng/052802.htm.

OREIRO, J.L. (2002). "Prêmio de risco endógeno, metas de inflação e câmbio flexível: implicações dinâmicas da hipótese Bresser-Nakano para um pequena economia aberta". Revista de Economia Política: 22 (3): 107-122, jul./set.

OREIRO, J.L, SICSÚ, J.S EPAULA, L.F. (2003). "Uma Alternativa Keynesiana para - Crescimento Sustentado da Economia Brasileira". In Anais do VIII Encontro Nacional de Economia Política. Florianópolis: Sogiedade Brasileira de Economia Política.

PAULA, L.F. (2003). "Uma alternativa de política econômica para o Brasil". Cadernos Adenauer, ano IV, n. 3, p. 39-92.

PAULA, L.F., OREIRO, J.L E JONAS, G. (2003). Fluxos e Controle de Capitais no Brasil: avaliação e proposição de política. Rio de Janeiro: Fundação Konrad Adenauer. 